\title{
New Methods of Application of Micro- Hydroelectric Power Plants at Existing Hydraulic Structures: Schemes, Parameters, Efficiency
}

\author{
$M$. Mukhammadiyev $^{1 *}, B$. Urishev ${ }^{2}, E . \operatorname{Kan}^{1}$ and $K$. Juraev $^{1}$ \\ ${ }^{1}$ Tashkent state technical university, 2 Universitet street Tashkent, Uzbekistan \\ ${ }^{2}$ Karshi engineering institute, 225 Mustaqillik street Karshi, Uzbekistan
}

\begin{abstract}
The structure of hydraulic structures of power and water management systems includes gates for various purposes, which allow you to regulate and distribute the flow of water in channels and waterworks. Existing gate designs do not provide for the possibility of generating electricity from the water energy of the stream passing through them. In order to convert the hydraulic energy of water passing through the gates into electrical energy a new patented design of the gate is proposed which allows using micro-hydroelectric power plants with a Banki turbine to make more rational use of the hydro resources of energy and water management systems. The proposed design solves the problem of expanding the functionality of the gate and increasing the efficiency of micro-hydroelectric power plants with a reduction in its cost. Areas of application of the new design for the combined use of micro-hydroelectric power plants and hydraulic gates at hydroelectric power systems are also proposed. The technique for determining the technical and economic parameters of microhydroelectric power plants installed on flat gates of hydraulic structures is given, and theoretical calculations are performed, which showed that the higher the capacity of micro-hydroelectric power plants, the shorter its payback period.
\end{abstract}

\section{Introduction}

In the development of one of the renewable energy sources, i.e. hydropower industry of the Republic of Uzbekistan, one of the important places is occupied by the use of energy potential of rivers, canals, water intake facilities, outfall and discharge facilities of reservoirs and other facilities for energy and economic purposes $[2,3,4,5]$. Use of hydraulic energy of intakes, spillways and outtakes opens up great opportunities for electricity generation $[3,4]$. The construction of low-pressure hydropower plants at such facilities will not require large material costs, so there is already a ready pressure head $[6,7,8,9,10]$. One of the important aspects in the analysis of hydropower potential of water intake, discharge and discharge facilities of energy and economic systems is the development of methods for determining

\footnotetext{
* Corresponding author: muhammadiyev_m@rambler.ru
} 
their water and energy indicators (hydropower parameters), taking into account their purpose and seasonal regulation $[5,6,8,11,12,13]$.

The relevance of the topic of the article lies in the fact that currently in the water system of the republic there are several tens of thousands of gates installed at culverts, spillways and regulated hydraulic structures of waterworks, irrigation canals, reservoirs, pumping stations $[2,3,4,14,15,16]$ and the installation of micro-hydroelectric power stations on them will allow more fully use the hydropower potential.

Operated gates of hydraulic structures are designed to open or close the spillway, water distribution in irrigation channels, etc. These gates are used in all hydroelectric and water management facilities and have various design versions: disk, flat, cone, etc. $[2,3,4,6,8$, $12,17]$.

The most common type of hydraulic gates in practice is flat gates $[2,3,4,6,8,12,17]$. The disadvantages of this gate are the limitation of its functionality and frequent changes in the position in the "working" and "non-working " modes, which require high energy consumption during its operation and lead to rapid failure of the gate seals. In addition, existing designs of a flat gate do not provide for the possibility of using water flow energy to generate electricity.

The article provides for the introduction into production of technical developments on the combined use of hydraulic locks with micro hydroelectric power stations, which allow more rational use of the water and energy resources of energy-water systems - devices for converting hydraulic energy of water into electrical energy using micro hydro power plants installed on flat gates of hydraulic structures [2, 3, 4, 8, 9, 17, 18, 19].

The novelty of the proposed technical solution is the design of a micro-hydroelectric power station on the gts gates, which significantly expands their functionality, and a method of feasibility study of the feasibility of their use.

Expanding the functionality of hydraulic facilities and hydraulic structures requires technical re-equipment with the development of new technical solutions in this area, as well as their use in the designed facilities of hydropower complexes [5, 7, 8, 9, 18, 19].

\section{Methods and Materials}

We have proposed a method of using water energy from a stream passing through a structure in the form of a new patented micro-hydro power plant design with Banks on flat gates of a hydraulic structure [20], which will allow more rational use of energy systems.

Flat gate of hydraulic structures serves for blocking the outlet opening and water passage from the upper to the lower one according to the task of the control center. The disadvantage of this shutter is the inability to use the hydraulic energy of the transmitted water to produce electrical energy $[2,3,4]$.

The task is solved by the fact that the gate containing the superstructure, the undercarriage additionally contains guide covers and a threshold, a well for placing electric power equipment and a microhydroelectric power station that has Banks as a hydro engine.

The gate of the hydraulic structure contains the span structure 1, support and running parts 2 , two turbines of the micro-hydroelectric power plant 3 , installed at the bottom of the structure behind the span structure 1 , generator 4 , connected to the turbine by means of the transmission mechanism 5, a streaming cover 6 and a threshold 7, a well to accommodate the electric power equipment 8 (Figure1).

The gate of the hydraulic structure works as follows. At opening of the gate span structure 1 , water directed by the lid 6 and threshold 7 enters turbines of small hydroelectric power plant 3 , which provides their rotation with generator 4 by means of transfer mechanism 5 . Generator 4 and other equipment (pulleys, multiplier, ballast, etc.) are located in well 8 , located in the center of the plumbing chamber between the turbines of small hydropower 
plants. The well is hermetically sealed along the perimeter with metal walls, and its bottom is located at the bottom of the structure.

To pass the water flow rate, which is larger than the capacity of the turbine, the lift of the span structure 1 of the gate is performed and the water is supplied to the lower elevator through the span located above the stream lids 6 .

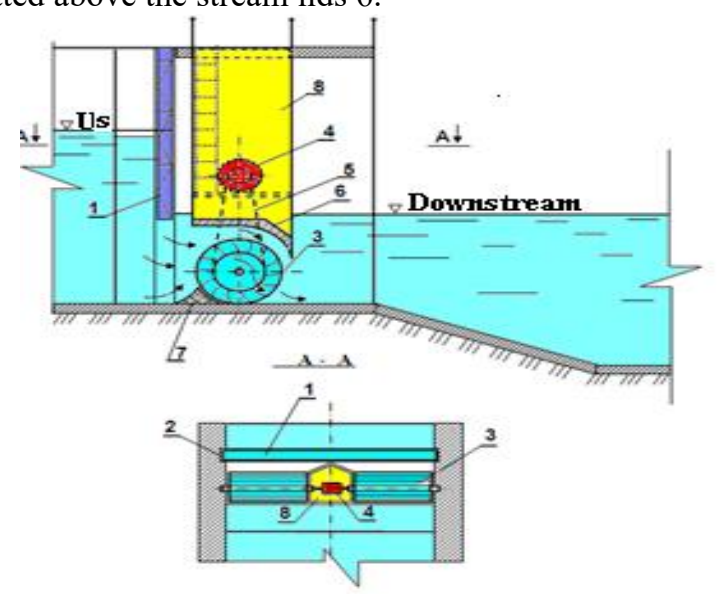

Fig. 1. Micro-hydroelectric power station with a turbine Banks on a flat gate: 1 - span structure; 2 supporting and running parts; 3 - two Banks' turbines; 4 - generator; 5 - connected to the turbine by means of the transmission mechanism; 6 - string guiding cover; 7 - threshold; 8 - well

When performing repairs, it is possible to lift the turbines up, since their axis is installed in the embedded parts of the structure and the well, and the guide cover is removable.

In the proposed design of the gate, guide covers and a threshold, a well for placing electric power equipment, and a Bank turbine are additionally installed. This ensures:

a) the possibility of supplying large water flows to the lower stream during the growing season, which is not present in conventional gate designs;

b) the efficiency of a small hydropower plant increases, since there is no turbine pipeline and valve, and the associated energy loss, in contrast to traditional designs of a small hydropower plant;

c) the turbine is located directly in the receiving zone of the water flow without any intermediate elements and the use of the guide cover and threshold provides a high degree of energy supply to the turbine, and all this, as a result, increases the efficiency of micro hydroelectric power station;

d) the use of the Bank's turbine due to the simplicity of manufacture and, accordingly, lower material costs of manufacturing, significantly reduces the cost of micro hydroelectric power stations.

A prerequisite for the widespread use of such hydraulic installations is their feasibility study, that is, the determination of the technical and economic parameters of micro hydroelectric power plants installed on the gates of hydraulic structures of hydroelectric power systems $[2,3,11,12]$.

The technical and economic parameters of micro-hydropower plants installed in the gate of the hydraulic structure of the hydroelectric power system should include $[6,7,11,12]$ :

- head of micro-hydroelectric power station;

- micro-hydroelectric power plant capacity;

- annual electricity generated by micro-hydroelectric power plants;

- capital investments to create micro-hydroelectric power plants at the existing gate;

- operating costs for micro-hydroelectric power plants; 
- cost of electricity generated by micro-hydroelectric power plants;

- saving fuel resources;

- net profit from the use of micro-hydroelectric power plants;

- payback period of micro-hydroelectric power plants.

Figure 2 shows one of the widely used schemes of the hydrosystem of the energy and economic system $[3,5,6,14,15,21]$.

In the diagram, from the reservoir formed by the dam, there is a supply channel with a zero slope of the bottom, at the end of which there is a regulator of the main channel.

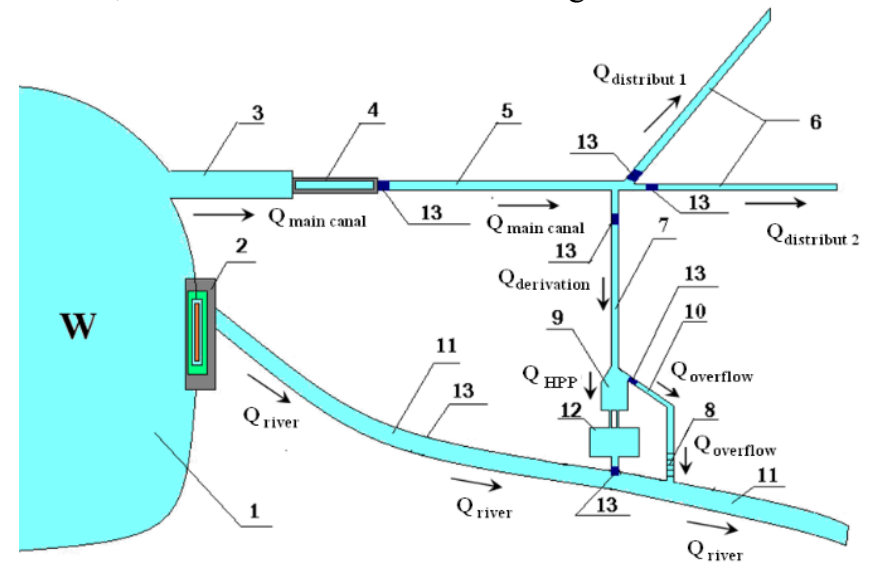

Fig. 2. Scheme of the hydroelectric power system: 1-reservoir; 2-dam; 3-inlet channel; 4-regulator of the main channel; 5-trunk channel; 6 - distributing canal; 7-derivation channel; 8-difference; 9pressure pool; 10-blank spillway; 11- river; 12 - derivational hydroelectric power station; 13 prospective installation sites for micro-hydro stations.

The main channel supplies water to the distributors and the hydroelectric power station's derivation channel. To supply water to the hydroelectric power station (HPP) building, a derivation channel departs from it, ending in a pressure pool, on the right side of which there is an idle spillway with a drop that connects the idle discharge with the lower stream of the river.

It can be seen from figure 2 that at several sections of the hydrosystem with installed hydraulic gates for water regulation it is possible to combine the use of micro HPP and hydraulic gates (13).

Figure 3 shows the scheme of using micro-hydroelectric power stations on the hydraulic gate of the channel. On the basis of this task, a method was developed for calculating the feasibility study of micro-hydroelectric power plants installed on the gate of a hydraulic structure. 


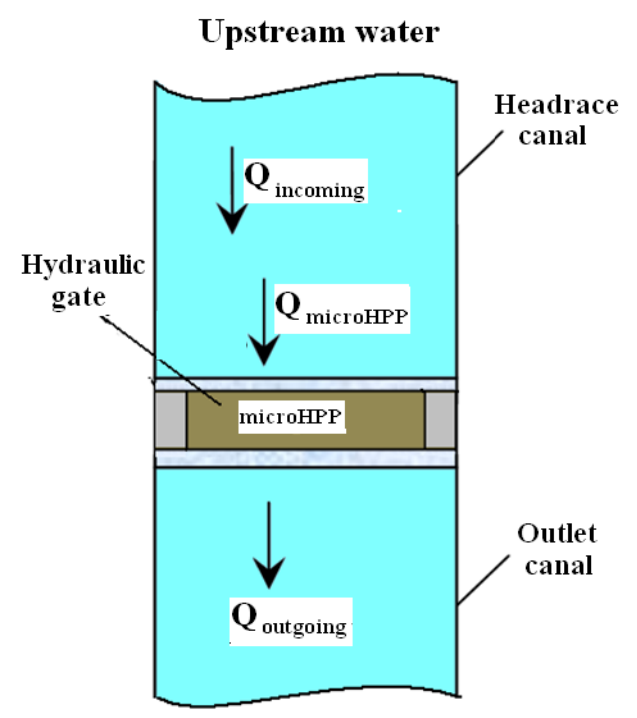

Downstream water

Fig. 3. Scheme for using the gate with micro-hydroelectric power plants: Qincoming - water flow through the supply channel; QmicroHHP - HPP consumption; Qoutgoing - water flow through the outlet channel.

The head of the micro-hydroelectric power plant is determined: $H=\left(\nabla U S+\frac{Q_{\text {incom }} \cdot t}{S_{\text {bottomUS }}}-\frac{Q_{\text {microHPP }} \cdot t}{S_{\text {bottomUS }}}\right)-\left(\nabla D S-\frac{Q_{\text {out }} \cdot t}{S_{\text {bottomDS }}}+\frac{Q_{\text {microHPP }} \cdot t}{S_{\text {bottomDS }}}\right)-h w,[\mathrm{~m}]$

where $\nabla U S$ - water mark to the shutter, i.e. the level of the upper stream (pool), m; $\nabla D S-$ water mark after the gate, i.e., a marker downstream micro hydroPP, m; $S_{\text {bottomUS }}$ and $S_{\text {bottomDS }}$ - square, bottom upper and lower pool, $\mathrm{m}^{2} ; h_{w}$ - pressure (head) loss for water conveyance tract micro hydroPP, $\mathrm{m} ; t$ - time of operation of micro hydroPP, sec.

The pressure loss in the water supply path of the micro-hydroelectric power station is determined by:

$$
h_{w}=1.1 \cdot \lambda \frac{L}{D} \cdot \frac{16 \cdot Q_{\text {microHPP }}^{2}}{\pi^{2} \cdot g \cdot D^{4}}=0.182 \cdot \lambda \cdot \frac{L \cdot Q_{\text {microHPP }}^{2}}{D^{5}},[\mathrm{~m}]
$$

where $L$ is the length of the water conveyance tract micro hydroPP, m; $D$-diameter water conveyance tract micro hydro, $\mathrm{m} ; \lambda$ - coefficient of hydraulic friction.

$$
\lambda=0.11 \cdot\left(\frac{\Delta e}{D}\right)
$$

where $\lambda$ - is the wall roughness coefficient.

Taking into account the continuity condition $Q_{\text {microHPP }}=Q_{\text {outgoing }}$, the pressure formula (1) will take the following form: 


$$
\begin{aligned}
& H=\left(\nabla U S+\frac{Q_{e n} \cdot t}{S_{\text {bottomUS }}}-\frac{Q_{\text {microHPP }} \cdot t}{S_{\text {bottomUS }}}\right)-\left(\nabla D S-\frac{Q_{e x} \cdot t}{S_{\text {bottomUS }}}+\frac{Q_{\text {microHPP }} \cdot t}{S_{\text {bottomUS }}}\right)-h w= \\
& =\nabla U S-\nabla D S+\frac{1}{S_{\text {bottomUS }}}\left(Q_{b x} \cdot t-Q_{\text {microHPP }} \cdot t\right)-h_{w},[m]
\end{aligned}
$$

If $t=1 \mathrm{sec}$, in this case the pressure is determined by the formula:

$$
H=\nabla U S-\nabla D S+\frac{1}{S_{\text {bottom } U S}}\left(W_{x x}-W_{\text {microHPP }}\right)-h w
$$

where $\mathrm{W}$ is the volume of water over time $\mathrm{t}$.

The full power of the micro HPP will be equal:

$$
N_{\text {microHPP }}^{\text {total }}=9.81 \cdot Q_{\text {microHPP }} \cdot H_{g},[\mathrm{~kW}]
$$

where $H_{g}$ is the geometric head of the micro-hydroelectric power station, which is determined by the following formula:

$$
H=\nabla U S-\nabla D S+\frac{1}{S_{\text {bottom } U S}}\left(W_{\text {incom }}-W_{\text {microHPP }}\right),[\mathrm{m}]
$$

The power of the micro HPP (useful) will be equal:

$$
N_{\text {microHPP }}=9.81 \cdot Q_{\text {microHPP }} \cdot H \cdot \eta_{H U},[\mathrm{~kW}]
$$

where $\eta_{H U}$ is the efficiency coefficient of the hydraulic unit of the micro HPP, $\%$.

If the entire incoming flow rate passes through the micro-hydroelectric power station $\left(Q_{\text {incom }}=Q_{\text {microHPP }}\right)$, then the power of the micro-hydroelectric power station will be equal to $[2,3,22,23]$ :

$$
N_{\text {microHPP }}=9.81 \cdot Q_{\text {incom }} \cdot H \cdot \eta_{H U},[\mathrm{~kW}]
$$

Capital investments for the creation of micro-hydroelectric power stations on the existing gate of a hydraulic structure are determined by the following formula:

$$
K_{\text {microHPP }}=N_{\text {microHPP }} \cdot k_{\text {specifik }},[\mathrm{USD}]
$$

$k_{\text {specific }}$ - specific investment per $1 \mathrm{~kW}$, (specific cost), USD/kW.

Annual electricity generated by micro-hydroelectric power plants:

$$
E_{\text {microHPP }}=N_{\text {microHPP }} \cdot T=9.81 \cdot Q_{\text {microHPP }} \cdot H \cdot \eta_{U S} \cdot T,[\mathrm{~kW} \cdot \mathrm{h}]
$$

$\mathrm{T}$ - the time of use of micro-hydroelectric power plants during the year.

Operating costs (maintenance charges) for micro-hydroelectric power plants are defined as:

$$
Z=Z_{1}+Z_{2}+Z_{3},[\mathrm{USD}]
$$

$Z_{l}$ - depreciation expenses: $Z_{I}=0.029 \cdot K$, [USD].

$Z_{2}$ - repair work: $Z_{2}=0.03 \cdot K$, [USD].

$Z_{3}$ - annual salary: $Z_{3}=m \cdot$ zsalary $\cdot 12$, [USD]. 
$m$ - the number of employees;

zsalary - monthly salary, us dollars.

Price of electricity generated by micro-hydroelectric power plants:

$$
P=E_{\text {microHPP. }} \cdot \beta,[\mathrm{USD}]
$$

$\beta$ - cost of $1 \mathrm{kWh}$ of electricity, USD/kWh.

The economy of fuel resources:

$$
R_{\text {fuel }}=E_{\text {microHPP. }} \cdot g,[\mathrm{~kg} \text { of standard fuel }]
$$

$g$ - specific consumption of standard fuel, $\mathrm{kg} /(\mathrm{kW} \cdot \mathrm{h})$.

Income from fuel economy:

$$
I_{\text {fuel }}=R_{\text {fuel }} \cdot P_{\text {fuel }}
$$

$P_{\text {fuel }}$ - the average price of $1 \mathrm{~kg}$ of conventional fuel, USD $/ \mathrm{kg}$.

Net profit from the use of micro-hydroelectric power plants:

$$
N_{p}=P_{\text {microHPP }}+I_{\text {fuel }}-Z
$$

Comparative economic efficiency coefficient:

$$
E=\frac{N_{p}}{K_{\text {microHPP }}} .
$$

Payback period $=1 / E$, [year].

Based on the created methodology, a special computer program was developed to determine the technical and economic parameters of the micro-hydroelectric power station used at the gate of hydraulic structures.

\section{Results}

Figure 4 shows the characteristics of the dependence of water flow, head and payback period on the power of a hydroelectric installation obtained from the results of calculating the technical and economic parameters of micro-hydroelectric power plants at the gate of hydraulic structures.

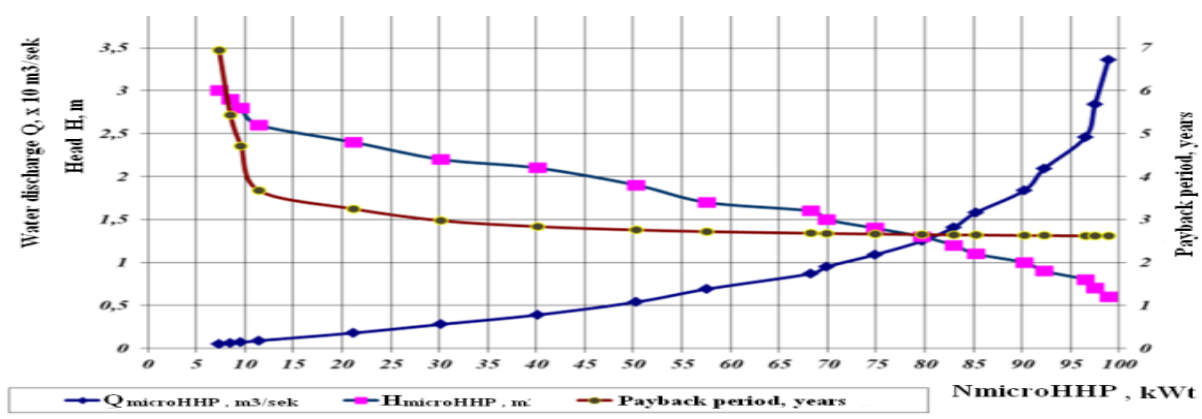

Fig. 4. Graph of the dependence of water consumption, head and payback period on the power of microhydroelectric power plants. 


\section{Discussions}

The research and calculations made it possible to determine a number of technical and economic indicators that allow not only to recommend approaches to the selection of parameters of micro-hydroelectric power plants at hydraulic structures, but also to justify their application in specific conditions of the region.

From the above conducted calculations to determine the technical and economic parameters of the used micro hydro gate hydraulic structures, we can say that the more power a micro hydro less the term of its recoupment, and thus the economic efficiency is increased. The limit value of the power at which the installation of micro-hydroelectric power plants on the gates of hydraulic structures is cost-effective, and the payback period is relatively small, is the power of $10 \mathrm{~kW}$.

\section{Conclusions}

The conducted calculations allowed us to justify the use of micro-hydroelectric power plants in specific conditions of the region on the basis of a number of technical and economic indicators.

The use of micro-hydroelectric power plants is almost always profitable, where watercourses provide installation of micro-hydroelectric power plants with a capacity of more than $10 \mathrm{~kW}$.

At the same time, it is desirable to divide micro-hydroelectric power plants into two groups, the first group - with a capacity of up to $10 \mathrm{~kW}$ and the second group with a capacity of more than $10 \mathrm{~kW}$. Micro-hydroelectric power plants of the first group can be installed on small watercourses with a flow rate of up to $1 \mathrm{~m}^{3} / \mathrm{s}$, and the second group - on watercourses of more than $1 \mathrm{~m}^{3} / \mathrm{s}$.

Micro-hydroelectric power plants of the second group with a capacity of more than 10 $\mathrm{kW}$ can be installed on almost all hydraulic structures with flat gates, on many water intake and culvert structures of water nodes, rivers and channels. Moreover, many water intake and culverts in our Republic can be installed micro -, mini-and small hydroelectric power plants with a capacity of $100 \mathrm{~kW}$ or even more, up to $500 \mathrm{~kW}$.

The energy potential of hydraulic gates (more precisely, water flows passing through them) of water intake, discharge and culvert structures of small rivers, rivers, channels of Uzbekistan is sufficient for their use in order to improve the power supply of individual and farm enterprises, small enterprises by creating micro-power plants.

With such plants, i.e. the use of micro hydro on gates hydraulic structures, it is possible to solve the issues of energy supply, conservation, and preservation of ecological purity, etc.

\section{References}

1. M. Mukhammadiev, B. Urishev, E. Mamadiyorov, Dzhuraev K.S. Low Power Plants on the Basis of Renewable Energy Sources. Monograph, T.: ToshDTU, 2015

2. F. De Lillo, F. Cecconi, G. Lacorata, A. Vulpiani, EPL, 84, 2008

3. M. Muhammadiev, K. S.Dzhurayev, B. U. Urishev. Increase of Use of Hydropower Potential of Low Power Irrigation Facilities with Application of New Design Gates. Journal "Vestnik TashGTU", № 2, 2015

4. M. M. Muhammadiev, S. Klychev, KS Dzhuraev. Investigation of Water Flow Velocity in Gates of Hydroelectric and Irrigation Facilities. Magazine "Vestnik SGASU: Urban Planning and Architecture", issue № 2, 2016

5. http://www.gidroproekt.uz/2020 
6. Hydroelectric stations. Guide for developers and investors, 2010 ww.ifc.org/wps/wcm/connect/06b2df8047420bb4a4f7ec57143498e5/hydropower_repo rt.pdf?mod=ajperes.

7. G. I. Sidorenko, I.G. Kudryasheva, V.I. Pimenov. Economics of the installations of the non-traditional and renewable energy sources. Technical and economic analysis: tutorial / Under general ed. Elistratova, G.I. Sidorenko, SPB.: Politekhi Publisher, Unta, 2008

8. Hydropower Texnology Roadmar 2012. http:// www. iea.org. 2012_hydropower_ roadmar.pdf (2012)

9. World Small Hydropower Development Report 2016. www.unido.org/sites/default/files/(2016) 11/wshpdr_executive_summary_2016_0.pdf

10. Renewable Power Generation Costs in 2018. https://www.irena.org//media/files/irena/agency/publication/2019/may/irena_renewable-power-generationscosts-in-2018.pdf

11. Asmae Berrada, Zineb Bouhssine, Ameur Arechkik. Optimisation and economic modeling of micro hydropower plant integrated in water distribution system. Journal of cleaner production, volume 232, 20 September 2019, (2019)

12. Muhammad Kamran, Rohail Asghar, Muhammad Mudassar, Muhammad Irfan Abid. Designing and economic aspects of run-of-canal based micro-hydro system on BallokiSulaimanki link canal-i for remote villages in Punjab, Pakistan. Renewable Energy, volume 141, October 2019, 2019

13. H. Bory, L. Vazquez, H. Martínez, Y. Majanne. Symmetrical angle switched singlephase and three-phase rectifiers: application to micro Hydro Power Plants. Ifacpapersonline, volume 52, issue 4, 2019

14. Petras Punys, Algis Kvaraciejus, Antanas Dumbrauskas, Linas Šilinis, Bogdan Popa. An assessment of micro-hydropower potential at historic watermill, weir, and nonpowered dam sites in selected eu countries. Renewable energy, volume 133, April 2019

15. T. Ueda, E. S. Roberts, A. Norton, d. Styles, J. Gallagher. A life cycle assessment of the construction phase of eleven micro-hydropower installations in the UK. Journal of cleaner production, volume 218, 1 May 2019

16. Yanlai Zhou, Li-Chiu Chang, Tin-Shuan Uen, Shenglian Guo, Fi-John Chang. Prospect For Small-Hydropower Installation Settled Upon Optimal Water Allocation: An Action To Stimulate Synergies Of Water-Food-Energy Nexus. Applied energy, volume 238, 15 March 2019

17. D. Singh: "Micro hydro power", resource assessment handbook, 2009

18. Small And Micro-Scale Hydropower in Japan. https://halshs.archivesouvertes.fr/halshs-01803429/document

19. Small Hydro Power in India. http://www.energynext.in/2017/03/small-hydro-power-inindia/

20. M. Muhammadiev, B.U. Urishev, K.S. Dzhuraev, S.R. Zhuraev and others. Water Intake Structure with Hydroelectric Power Station. Patent UZ IAP №05378, №4, 28.04.2017.(2017)

21. Shibabrata Choudhury, Adikanda Parida, Rajive Mohan Pant, Saibal Chatterjee. GIS augmented computational intelligence technique for rural cluster electrification through prioritized site selection of micro-hydro power generation system. renewable energy, volume 142, november 2019 
22. Hossein Iman-Eini, David Frey, Seddik Bacha, Cedric Boudinet, Jean-Luc Schanen. Evaluation of loss effect on optimum operation of variable speed micro-hydropower energy conversion systems. Renewable energy, volume 131, february 2019

23. E. B. Kengne Signe, Bachirou Bogno, Michel Aillerie, Oumarou Hamandjoda. Performance in feasibility studies of micro hydro power plants. new software development and application cases in Cameroon. energy procedia, volume 157, january 2019

24. A. D.Girgidov. Fluid and gas mechanics (hydraulics): textbook. 2nd ed., pp. i dop. Moscow: Infra-M, 2020 